\title{
ASSESSMENT OF THE STATUS OF PRIVATE AND NON-GOVERNMENTAL PHARMACEUTICALS SUPPLY WAREHOUSES IN GAZA STRIP, PALESTINE.
}

\author{
MOHAMMED TABASH*, MAZEN ABUQAMAR \\ Department of Faculty of Applied Medical Sciences, Al-Azhar University, Gaza, Palestine. Email: mohtabash@gmail.com
}

Received: 18 September 2017, Revised and Accepted: 18 November 2017

ABSTRACT

Objective: Storage of medicine is one of the most important stages in the pharmaceuticals and medical preparations management, which influences the quality and the effectiveness of these products. The study was conducted to assess the storage system of the drugs, medical disposables and their management in the private and local NGOs medical warehouses in Gaza Strip.

Methods: A cross-sectional study using interviewing questionnaire and checklist was carried out at (16) local NGOs including 33 employees and (29) private warehouses including 57 employees.

Results: The quality of construction of private and local warehouses were enough satisfied (80\%), while stock management and quality control were in a need to improvement (44.5\%), in which the quality of stock control and conditions of local NGOs were higher than private warehouses. Inadequate training courses were given in store related work. The majority of warehouses did not have practical guidelines and written procedures for dealing with storage procedure; also, there is inadequate safety and security system. About $37 \%$ of them kept controlled drugs in a separate storage space designated for this purpose. More than half of warehouses always quarantined medical supplies until the quality is checked. $60 \%$ of warehouses used first expire first out dispensing policy for medical supplies. $56 \%$ of the warehouses measure temperature, while not all warehouses measured humidity.

Conclusion: Warehouses need to pay attention to the commodity management cycle and to ensure the availability of safety measurements. Provision of training to employees dealing with the storage process is essential accompanied by monitoring and supervision.

Keywords: Pharmaceuticals supply, Quality control, Storage condition, Stock Management, Medical warehouse.

(C) 2018 The Authors. Published by Innovare Academic Sciences Pvt Ltd. This is an open access article under the CC BY license (http://creativecommons. org/licenses/by/4. 0/) DOI: http://dx.doi.org/10.22159/ajpcr.2018.v11i2.22639

\section{INTRODUCTION}

Maintaining appropriate storage conditions for health commodities is vital to ensuring its quality. Product quality is based on ideal storage conditions and protection of products' quality until their expiration date is important for serving customers and conserving resources [1-3].

All buildings should be maintained clean, large enough, constructed and located in a way to facilitate cleaning and maintaining of good storage conditions of drugs and drug products [4,5]. All building should be well lighted and ventilated. All floors, walls, ceilings, tables, and other fixtures should be constructed in a way that they may be easily cleaned [6]. Pharmacists and pharmaceutical technologists are responsible for ensuring that products/materials are correctly handled stored and distributed. They should have the education, training experience or combination of these elements that will allow them to effectively discharge this responsibility [7].

Controlled storage environments (deep freeze, refrigerators) should be monitored using suitable temperature recording devices, and the records should be filled and reviewed. Temperatures in other areas where goods requiring specific storage conditions are held should be monitored and the results tabulated and analyzed to demonstrate the suitability of these areas for their purposes [6].

Each medical warehouse should maintain a standard list of stock items that include all products they handle, with their specifications, including form, and quantity per package. The list should be regularly updated and distributed to sub-stores and units. Records of all stocks received their sources, batch numbers, expiry dates, and quantities received should be maintained [8].
Proper storage conditions for pharmaceutical products and paramedical supplies are vital to ensure their quality, safety, and efficacy. Successful storage should maintain the received drugs in the same quantity and quality until they are issued and minimize stock holding costs while maintaining acceptable service level.

Since the starts of Al-Aqsa Intifada in September 2000, the pharmaceutical sectors have been suffering the consequences of the prevailing political situation, ranging from closure and siege imposed on the Palestinian people in Gaza Governorates. Huge amount of uncoordinated donations was received. Subsequently, lot of these donations were damaged or expired due to inadequate storage conditions. However, the process of drugs and disposable storage at local NGOs and private warehouses has not been studied, therefore, investigation of this issue is important to improve the current storage system and the potential corrective measures.

\section{METHODS}

The study was conducted in private and local NGO warehouses located in Gaza Strip. A cross-sectional study was designed and conducted using interviewing questionnaire and checklist according the criteria proposed by the World Health Organization (WHO) and Pharmaciens Sans Frontiers to evaluate the quality of pharmaceutical inventory management system at medical warehouses facilities. The study was conducted at (16) local NGOs including 33 employees and (29) private warehouses including 57 employees. Any employee who has no direct responsibilities in the storage procedures, such as secretaries, cleaners were excluded.

In detail, through questionnaire and checklist, the assessment involves gauge the infrastructure, storage facility conditions, arrangement of 
stock keeping units, logistic skill level of personnel, and other secondary recordkeeping approaches such as stock record ledgers and bin cards. Along with the checklist, the logistic skills of the personnel dealing with the supply of pharmaceutical needs including the medical officer and the pharmacist was assessed with an interviewing questionnaire with their willingness to participate in the assessment. Formal approval from the manager and employees in each warehouse was obtained. Confidentiality of the data was maintained

The questionnaire consists of three domains: Construction domain consisted of four questions about receiving checking, distribution, assembly area, and loading bay. In addition, there was a question refers to the quality of construction such as store location, entrance, and area. Quality control process domain consisted of 11 questions checking of physical features, expired date, and recording of stock. Store management domain consisted of four questions about availability of written regulations, practical guidelines, computerized software, and designed vehicle. The checklist consisted of two domains: Storage conditions domain with eight questions about security and safety procedures, air-condition, temperature, humidity instrument, and electricity generator. Physical condition domain consisted of 12 questions about construction quality, light, ventilation, temperature, and quality of items.

Data were collected, revised, coded and entered into statistical software (Statistical Package for the Social Sciences) SPSS version 24. For the statistical analysis of our data, several applications of descriptive and inferential analysis were used. Descriptive statistics such as frequencies in cross-tabulations were used to describe the main features of the data and to study the first-hand relationship between the variables. Statistical associations between pairs of categorical variables were assessed using Chi-square tests. Since the outcome, measures are all introduced to the analyses as domain (continuous), t-test and ANOVA models were used when dealing with manifest variables. 95\% confidence intervals (CIs) were calculated as estimates of odds ratios. A significant result means that the $\mathrm{p}$-value for the ordinal level measure is $<0.05$ and the CIs is $95 \%$.

\section{RESULTS}

\section{Sociodemographic of the study population}

The results showed that the respondents from the private medical warehouses represented $63.3 \%$, while local non-governmental warehouses represented $36.7 \%$ and the majority of employees were male $(86.6 \%)$, however, about $30 \%$ of local NGOs were female. The revealed dominance of male workers in warehouses is inconsistent with the previous study on governmental central medical warehouse management system that shows that there were no obvious gender variations [9] (Table1).

About $65 \%$ of employees have a bachelor degree, and $30 \%$ of employees have diploma. 58\% are pharmacists, while 29\% are pharmacist assistants, $13.5 \%$ have other specializations (nurses, engineers or information technology). About $44 \%$ of employees had experienced $<4$ years, and $41 \%$ had experience between 4 and 10 years, while $15.5 \%$ of the employees had experienced more than 10 years. The guidelines for good storage practices in medical store and hospitals of Egypt indicated that the personnel who carry out supervision and/or controlling functions should possess the necessary knowledge, experience, and qualification to ensure maintaining the quality of the product [8]

Adequate training program is very necessary for the improvement of efficiency and effectiveness of work; however, changes in work behavior led to improvement and efficient functional system [10,11]. Progressive warehousing organizations now train their staff at all levels in practical and organizational skills that will improve the efficient running of their business [6]. Greater efficiency will reduce costs [12]. The results showed that training was limited, only $16 \%$ of employees in medical warehouses had received training courses in store work and $83 \%$ of them did not receive any training courses. Adequate training program is very necessary because it increases the efficiency and effectiveness of work [11]. They should receive initial and continuing training relevant to their tasks, and be assessed as applicable, in accordance with a written training program [13]. Proper training programs are essential for safety measures, particularly in reducing the risk of accidents and avoid threats to health. All warehouse operations, physical and managerial can be made more efficiently through proper training [8]. All personal in NGOs medical warehouses should receive proper training in relation to good storage practices, regulations, procedures, safety, and accountability.

\section{Setting up of the medical warehouses}

About $67 \%$ of warehouses which had inward and outward flow of medical supply are going through one entrance while the rest flow supplies from two entrances on either on the same side or different sides of the building.

The findings are inconsistence with guidelines, which indicate that a pharmaceutical warehouse should be easily accessible, well-situated, well-laid out, tidy, clean, and well secured [7]. The store must be accessible with adequate security system [6]. The guideline of the WHO, 1993 recommended that inward entrance should be different from the outward entrance to avoid disturbance between receiving and

Table 1: Distribution of respondents based on sociodemographic factors

\begin{tabular}{|c|c|c|c|}
\hline & Private $n=57(\%)$ & Local NGOs n=33 (\%) & One sample t-test (percentage $P$ value) \\
\hline Type of warehouse & $57(63.3)$ & $33(36.7)$ & $2.6(0.010)$ \\
\hline \multicolumn{4}{|l|}{ Gender } \\
\hline Male & $55(96.5)$ & $23(69.7)$ & $2.1(0.045$ \\
\hline Female & $2(3.5)$ & $10(30.3)$ & $4.9(0.000)$ \\
\hline \multicolumn{4}{|l|}{ Qualifications } \\
\hline Diploma & $19(33.3)$ & $14(42.4)$ & $0.9(0.321)$ \\
\hline Bachelor & $38(66.7)$ & $19(57.6)$ & $0.7(0.439)$ \\
\hline \multicolumn{4}{|l|}{ Specializations } \\
\hline Pharmacist & $32(56.1)$ & $20(60.6)$ & $0.3(0.693)$ \\
\hline Pharmacist assistants & 15 (17.5) & $11(33.3)$ & $2.1(0.033)$ \\
\hline Other specialties & $10(26.3)$ & $2(6.1)$ & $3.6(0.001)$ \\
\hline \multicolumn{4}{|l|}{ Experience years } \\
\hline$<4$ years & $22(38.6)$ & $17(51.5)$ & $1.3(0.196)$ \\
\hline Between 4 and & $26(45.6)$ & $11(33.3)$ & $1.3(0.191)$ \\
\hline 10 years & & & \\
\hline More than 10 years & $9(15.8)$ & $5(15.2)$ & $0.1(0.918)$ \\
\hline \multicolumn{4}{|l|}{ Receiving training } \\
\hline Yes & $10(17.5)$ & $5(15.2)$ & $0.4(0.704)$ \\
\hline No & 47 (82.5) & $28(84.8)$ & $0.2(0.866)$ \\
\hline
\end{tabular}


distribution processes which must be performed in all medical supply of NGOs warehouses [5]. This study was consistent with the study conducted by Al-Geeg in governmental central warehouse that showed warehouse medical supplies were flown from the same entrance [9].

The nature of warehouse area depends on the warehouse type and the volume of stock storage, As shown in Table 2, nearly 50\% of warehouse's area were between 60 and $170 \mathrm{~m}^{2}, 38 \%$ of them were between 180 and $300 \mathrm{~m}^{2}$, and $12 \%$ were between 300 and $2000 \mathrm{~m}^{2}$. However, storage area should be of sufficient capacity to allow the orderly storage of the various categories of pharmaceuticals products, namely, bulk and finished products, products in quarantine, and released, rejected, returned, or recalled products [12]. According to good storage practice in Egypt (2009), the warehouse area must be more than $500 \mathrm{~m}^{2}$ to be sufficient for all storage practice [14]. After Israel military operation on the Gaza Strip, the control and coordination with the donations were further complicated. Many NGOs received drugs that did not pass through the central drugs store, so large quantity of incoming donations and the need to deliver large volumes of supplies very rapidly to the healthcare facilities exceeded their capacity to track them, so the area of their warehouses were insufficient [15]. Overstocked items on shelves, mean insufficient area for the proper arrangement to avoid any disturbance in stock management and distribution process. This result is consistent with study conducted by Al-Geeg, 2004 in governmental central warehouse, which showed that the store size was insufficient to store the required stock.
Well-planned medical store should have an ancillary area to the warehouse, adequate offices situated to permit good supervision of store, sufficient packing, and receiving area [3]. $82 \%$ of warehouses had special areas for receiving and checking medical supplies; 53.3\% of participants were perceived as sufficient, $31 \%$ of the perceived as acceptable and $15 \%$ of employee reported, it is insufficient or not available. Furthermore, $57 \%$ of employees reported that distribution area for medical supply is sufficient, $31 \%$ of them said, it is acceptable, while $12 \%$ of them considered it as insufficient or not available. These results were inconsistent with Al-Geeg study, 2004 in governmental central warehouse that showed no specific area for receiving, checking, and distribution. Receiving and dispatching bays should be sufficient for all shipments and had adequate space for loading and unloading bay. Moreover, these bays should have a suitable height exceeding the height of vehicle [7].

Regarding assembly area, $55.5 \%$ of employees reported that assembly area of medical warehouse was sufficient, $32 \%$ of them considered it as acceptable, $15 \%$ of considered it is insufficient or not available. However, all private warehouses had assembly area, which considered sufficient. Loading and unloading bay were sufficient as reported by about $67 \%$ of respondents and $15 \%$ of them considered it insufficient or not available.

The results revealed half of respondents having a pharmacist who is responsible about the receiving medical supplies process, $28 \%$

Table 2: Warehouses construction and receiving process

\begin{tabular}{|c|c|c|c|}
\hline & Private $n=57(\%)$ & Local NGOs n=33 (\%) & Total $n=90(\%)$ \\
\hline \multicolumn{4}{|l|}{$\begin{array}{l}\text { Area of the warehouse (based on reported } \\
\text { response) }\end{array}$} \\
\hline $60-170 \mathrm{~m}^{2}$ & $30(52.6)$ & $14(42.4)$ & $44(48.8)$ \\
\hline $180-300 \mathrm{~m}^{2}$ & $25(43.9)$ & $10(30.3)$ & $35(38.8)$ \\
\hline $310-2000 \mathrm{~m}^{2}$ & $2(3.5)$ & $9(27.3)$ & $11(12.2)$ \\
\hline \multicolumn{4}{|l|}{ Flow of medical supply is from } \\
\hline One entrance & $38(66.7)$ & $23(69.7)$ & $61(67.7)$ \\
\hline Two entrances on the same side & $7(12.3)$ & 7 (21.2) & $14(15.5)$ \\
\hline Two entrances on different side & $12(21.1)$ & $3(9.1)$ & 15 (16.6) \\
\hline \multicolumn{4}{|l|}{ Sufficiency of receiving and checking area } \\
\hline Sufficient & $37(64.9)$ & $11(33.3)$ & $48(53.3)$ \\
\hline Acceptable & $17(29.8)$ & $11(33.3)$ & $28(31.1)$ \\
\hline Insufficient or Not available & $3(5.3)$ & $11(33.3)$ & $14(15.5)$ \\
\hline \multicolumn{4}{|l|}{$\begin{array}{l}\text { Sufficiency of distribution area and } \\
\text { assembly area }\end{array}$} \\
\hline Sufficient & $37(64.9)$ & 14) 42.4) & $51(56.6)$ \\
\hline Acceptable & $18(31.6)$ & 10) 30.3) & $28(31.1)$ \\
\hline Insufficient or Not available & $2(3.5)$ & $9(27.3)$ & $11(13.3)$ \\
\hline \multicolumn{4}{|l|}{ Sufficiency of loading and uploading bay } \\
\hline Sufficient & $38(66.7$ & $22(66.7)$ & $60(66.7)$ \\
\hline Acceptable & $10(17.5)$ & $6(18.2)$ & $16(17.8)$ \\
\hline Insufficient or Not available & $9(15.8)$ & $5(15.1)$ & $14(15.5)$ \\
\hline \multicolumn{4}{|l|}{$\begin{array}{l}\text { Approach for checking medical supplies at } \\
\text { the receiving stage }\end{array}$} \\
\hline Counting boxes & $2(3.5)$ & 0 & $2(2.2 \%)$ \\
\hline Counting items inside the boxes & $5(8.8)$ & $2(6.1)$ & 7 (7.7) \\
\hline $\begin{array}{l}\text { Counting boxes and items inside the } \\
\text { boxes }\end{array}$ & $50(87.7)$ & $31(93.9)$ & $81(90)$ \\
\hline \multicolumn{4}{|l|}{$\begin{array}{l}\text { The drugs and disposable are quarantined } \\
\text { till the quality checked }\end{array}$} \\
\hline Always & $35(61.4)$ & $23(69.7)$ & $58(64.4)$ \\
\hline Sometime & $17(29.8)$ & $6(18.2)$ & $23(25.5)$ \\
\hline Rarely & $5(8.8)$ & $4(12.1)$ & $9(10)$ \\
\hline $\begin{array}{l}\text { Physical check was done in the } \\
\text { warehouse }\end{array}$ & $7(12.3)$ & $2(6.1)$ & $9(10)$ \\
\hline \multicolumn{4}{|l|}{$\begin{array}{l}\text { Method of recording received drugs and } \\
\text { disposables movement }\end{array}$} \\
\hline Manual by use stock card & $7(12.3)$ & $3(9.1)$ & $10(11.1)$ \\
\hline Computer & $29(50.9)$ & $15(45.5)$ & $44(48.8)$ \\
\hline Both & $21(36.8)$ & $15(45.5)$ & $36(40)$ \\
\hline Notes are recorded in receiving invoice & $48(84.2)$ & $33(100)$ & $81(90)$ \\
\hline
\end{tabular}


reported having pharmacist assistants, and 22\% reported having other specialties (nurses, accountant, and information technology). Adequate number of competent personnel (pharmacists) should be involved in all stages of the distribution of pharmaceutical products to ensure that the quality of the product is maintained [14].

Only $2 \%$ of employees reported checking the amount of medical supply by counting boxes. Furthermore, $8 \%$ of them counted the items inside the box, while $90 \%$ of them counted the box and item (Table 2). However, 65\% of respondents reported that medical supplies were always quarantined till the quality is checked, $25 \%$ of them reported sometimes doing that, and $10 \%$ of them reported rarely doing that. When a drug shipment received contents, should be quarantined until they have been checked. The receiving clerks systematically check the boxes and their contents against the supplier's invoice. It is inspected to be sure that it meets the specifications in the supply contract and that the correct quantities are received [4]. In 2004, study of Al-Geeg in governmental central warehouse was consistent with this result, which showed that nearly all employees were checked the mount of received drugs and disposable by counting the box and item inside it.

The majority of respondents $(90 \%)$ reported that warehouses staff did not physically check medical supplies. $10 \%$ of them recorded received supplies manually while about half of them used computer and the rest used both manual and computer methods, in addition, $90 \%$ of respondents reported recording notes applied in the receiving invoice. Of respondents, $67 \%$ reported that storing the controlled drugs in their medical warehouse (Table 2). A physical inventory check is very important to be applied in warehouse. It helps to ensure that the stock on hand balances recorded on stock keeping records matches the quantities of products actually in the store when conducting a physical inventory, they should count each product individually by generic name, dosage form, and strength is essential [3].

Some products need storage in an access-controlled environment. These products (narcotics, psychotropic drugs) should be managed independently based on management policies specific to these products and under the responsibility of a pharmacist. Narcotics and other controlled products will be stored separately, in a locking cabinet (or little room), which will be guarded by the responsible pharmacist [7].

\section{Stock quality control}

Half of private warehouses while $70 \%$ of local NGOs warehouses arranged stock according to their expired date, and the rest of them used other methods or did not follow any arrangement, however, most of them (90\%) checking expire date periodically by checking computer or record on the label of the item (61\%). 54\% of warehouses is inserting a distinguish mark for medical supplies that have short expire date (Table 3). The study findings showed that more than half of warehouses storage arrangement adopted the global criteria. The global criteria reported that within warehouses and storerooms, drugs should be arranged according to specified organizational principles and using supply chain network [16]. Therapeutic/pharmacological class, clinical indication, alphabetic order, and level of use are commonly used principles. Within the warehouse itself as well as in clinical facilities, the use of the therapeutic/pharmacological classification produces good results; perhaps because, it provides a frame of reference within which workers can easily recognize individual products [8]. Always stuff should be arranged according to expiry date issue products that will expire first, ensuring they are not too close to or past their expiration date. The shelf life remaining must be sufficient for the product to be used before the expiry date that minimizes wastage from product expiry [3].

Periodic determination of expiration date of medicine at least 1 month in advance is essential if it is a very large warehouse, where a physical inventory can be carried out twice or 3 times a year [7]. Checking the time remaining before the expiration date against the time, covered by the quantities still in stock (the average monthly consumptions of the products must be known); making visible the products expiring within predefined time (for example, in 6 months or in 9 months) by marking them and use the products marked first is important. Hence, employees in NGOs warehouses should pay attention and put distinguished mark for drugs and disposable, which had short period expire date to manage it properly. They should start dispensing first, to ensure a minimum period of preservation.

Products received most recently may expire sooner than the products received earlier. Therefore, it is extremely important to always check the expiration dates and to make sure the dates are visible while the products are in storage [3]. The expiration date must appear on the package and/or on the product [8].

Regarding expired medical supplies, $77 \%$ of warehouses had a disposable system for damaged and expired supplied followed as recommended by ministry of health, however, $73 \%$ of them have damaged drugs and disposable, and the possible reasons for that were expired date $(97 \%)$ and ordering issue $(12 \%)$ (Table 3). The management of outdated products must follow a standardized operational procedure for the destruction of this expired stuff. Indeed, if we could not avoid expiry, expired drugs should be destroyed due to the risks related to their usage so, first, the expired products should be removed from the stock of products, placed in a reserved area of the store that can be locked (risks of theft). Second, these products are sorted by form to be destroyed in compliance with the law and the regulation in force in the country, and with the guidelines for safe

Table 3: Stock management and quality control process

\begin{tabular}{|c|c|c|c|}
\hline & Private $n=57(\%)$ & Local NGOs n=33 (\%) & Total $n=90(\%)$ \\
\hline \multicolumn{4}{|l|}{ Quality control process } \\
\hline Arrangement of drugs according to expire date & $29(50.9)$ & $24(72.7)$ & $53(58.8)$ \\
\hline Checking expiry date & $56(98.2)$ & $33(100)$ & $89(98.8)$ \\
\hline Checking expire date using computer record & $32(56.1)$ & $23(69.7)$ & $55(61.1)$ \\
\hline Checking expire date using the label of the item & $35(61.4)$ & $18(54.5)$ & $53(58.8)$ \\
\hline Distinguish mark for medical supply having short expire date & $23(40.4$ & $25(75.8)$ & $48(53.3)$ \\
\hline There is disposable system for expired medical supplies & $39(68.4)$ & $31(93.9)$ & $70(77.7)$ \\
\hline Possible damage of drugs and disposable due to expire date & $55(96.5)$ & $32(97)$ & $87(96.6)$ \\
\hline $\begin{array}{l}\text { Possible damage of drugs and disposable due to ordering issue } \\
\text { Management system }\end{array}$ & $3(5.3)$ & $8(24.2)$ & $11(12.2)$ \\
\hline Availability of practical guideline & $2(3)$ & $3(9)$ & $5(5)$ \\
\hline $\begin{array}{l}\text { Availability of written regulations for receiving, storing, and } \\
\text { distribution procedures }\end{array}$ & 7 (12.3) & $15(45.5)$ & $22(24.4)$ \\
\hline Availability of software in the warehouse & $44(77.2)$ & $28(84.8)$ & $72(80)$ \\
\hline $\begin{array}{l}\text { Availability of a vehicle to distribute the drugs and disposables } \\
\text { designated for medical warehouse use only (need special conditions) }\end{array}$ & $31(54.4)$ & $16(48.5)$ & $47(52.2)$ \\
\hline
\end{tabular}


disposal of unwanted pharmaceuticals. According to these principles, destruction is compulsory to guarantee the protection of public health and the preservation of the environment [7].

\section{Warehouse management system}

The principles of quality management system state the need for continuous improvement as one of the goals of the organization [17]. The study results confirmed that nearly all medical warehouses did not have approved practical guideline which is recommended to standardized all storing process in every warehouses and only $24 \%$ of warehouses having a written regulation for receiving, storing, and distribution procedures; however, half of them were non-governmental warehouses, while about $90 \%$ of private warehouses have not (Table 3 ). The researcher found that it is hard to get a copy of these regulations. Written instructions and records should be available to document all activities required in the storage areas including the handling of expired stock. These should adequately describe the stored procedures and define the route of materials and pharmaceutical products and information through the organization in the event of a product recall being required [3].

$80 \%$ of non-governmental medical supply warehouses used computer software in their work. The use of computers can facilitate, but not replace efficient procedures in pharmaceutical procurement. When implemented appropriately, computerization will speed up complex tasks, increase accuracy and automate repetitive tasks. Staff must be trained adequately in the use of computerized systems. Many aspects of procurement are suitable for computerization, including planning of requirements, budget management, and financial analysis, preparation of documentation, and reports and inventory control. Hard copies (printouts) should be produced as required to provide documented evidence of the activities. Where computer systems are not used, manual systems should provide documented evidence of the activities performed $[12,18]$. These results were inconsistent of Al-Geeg study that showed no computer software was used in the warehouse.

Half of them had a vehicle to distribute the drugs and disposables designated for medical warehouse use only (need special conditions). The guideline of the WHO reported that a vehicle and equipment should be used to distribute, store or handle pharmaceutical products. It should be suitable for their use and appropriately equipped to prevent exposure of the products to conditions that could affect their stability, packaging integrity, and prevent contamination of any kind [12].

The design and use of vehicles and equipment must aim to minimize the risk of errors and permit effective cleaning and/or maintenance to avoid contamination, build-up of dust or dirt and/or any adverse effect on the quality of pharmaceutical products being distributed. Dedicated vehicles and equipment should be used, where possible, when handling pharmaceutical products [6].

Procedures should be in place for the operation and maintenance of all vehicles and equipment involved in the distribution process, including cleaning and safety precautions. Vehicles, containers, and equipment should be kept clean, dry, and free from accumulated wastes. A written cleaning program should be available, indicating the frequency of cleaning and the methods to be used [12]. Refrigerated vehicles/transportation containers should be mapped and monitored if they provide the primary means for environmental control. However, this is not necessary if a qualified insulated container is used as the primary means of environmental control [19]. These results were inconsistent with Al-Geeg study that showed there was no vehicle to distribute drugs and disposables designed for the medical warehouse.

\section{Checklist resultsw}

\section{Storage conditions}

The observation results showed that more than half of the warehouses did not have emergency doors as well as emergency alarms and anti-theft security systems while more than $80 \%$ of them had fire extinguishers (Table 4). These findings showed that there were inadequate safety measures in NGOs warehouses workplace that requiring immediate emergency exit to ensure the safety of employees. The international guidelines for safety reported clearly the mark of emergency exits and should be checked regularly to be sure, they are not blocked or inaccessible [3]. Fire exits, corridors, walkways, doorways, and other points requiring immediate access must be clearly defined and kept free from obstruction and litter. Regular fire evacuation drills must be carried out [8]. These findings were inconsistent with the international guidelines that indicated, "To prevent damage of products from fire make standard fire extinguishers available in every storage facility according to national regulations." For example, visually inspect fire extinguishers every 2-3 months to ensure that pressures are maintained, and the extinguisher is ready for use. Smoke detectors throughout the storage facility should be in place and check them every 2-3 months to ensure that they are working properly and display fire precaution signs in appropriate places in the storage facility, especially locations where flammables are stored" [3].

The results showed that the anti-theft security system is not adequately applied in the warehouses, which are not in line with the international standards. Actual procedures should be taken to prevent unauthorized access to pharmaceutical products during transport. The store should be designed with security in mind. A strong security system can minimize shortage, minimize abuse or misuse, and contribute to accurate record keeping on drug consumption and disease prevalence [7].

The cost of security precautions should be related to the social environment in which the facility is situated and the value and nature of the goods used. Where large or significant quantities of valuable materials are held or where theft is prevalent, 24-h security coverage should be provided [8]. A study conducted in Lebanon by the WHO showed that the central medicines warehouse has no security management system in place, no monitoring on entry and exit, no alarm system and no searching security system is used [20]. To conclude, there is a need to maintain adequate security system to minimize shortage, minimize abuse and misuse at NGOs warehouses.

Regarding refrigerator and freezers temperature measuring device $55 \%$ of warehouses had well function thermometer and the temperature measurement and monitoring by staff and about $67 \%$ had air conditions, however, not all warehouses had humidity measurement instruments, and $87 \%$ of private warehouses had electricity generators while all NGOs warehouses had it (Table 4).

This finding was supported by the guideline of John Snow Inc. when reported that arrange for a generator or alternative supply of electricity for cold rooms and refrigerators if the main source of electricity is not reliable [3].

In this study, the results showed that the temperature of the warehouse is not monitored adequately, which is not appropriate according to the international standard which stated that the room temperature should not exceed $25-30^{\circ} \mathrm{C}$ and must be controlled, measured, and recorded on the appropriate sheet every day [7].

The temperature in the warehouse where medical supply requiring specific storage conditions is held should be monitored and the results tabulated and analyzed so as to demonstrate the suitability of these areas for their purposes $[3,21]$.

The study results showed that there were no signs of water drainage and leakage. Almost all of the warehouses had no any cracks or signs of humidity on the walls; $80 \%$ of the storage rooms were clean. This result means that almost all the storage places were in good condition. The walls and floors of the medical store should be smooth for easy cleaning [3]. Storeroom should have a specific environmental control of particulate and microbial contamination, constructed and used in 
Table 4: Warehouses storage conditions

\begin{tabular}{|c|c|c|c|}
\hline & Private $n=57(\%)$ & Local NGOs n=33 (\%) & Total $n=90(\%)$ \\
\hline \multicolumn{4}{|l|}{ Store conditions } \\
\hline Availability and use of emergency door/s & $22(38.6)$ & $13(39.4)$ & $35(38.8)$ \\
\hline Availability of emergency alarms & $20(35.1)$ & $19(57.6)$ & $39(43.3)$ \\
\hline Availability of anti-theft security systems & $17(29.8)$ & $11(33.3)$ & $28(31.1)$ \\
\hline Availability of fire extinguishers & $52(91.2)$ & $30(90.9)$ & $82(9.1)$ \\
\hline $\begin{array}{l}\text { Availability of refrigerator and freezers temperature measuring } \\
\text { device (thermometer) }\end{array}$ & $46(80.7)$ & $9(27.3)$ & $55(61.1)$ \\
\hline Availability of humidity measurement instruments & 0 & 0 & 0 \\
\hline Availability of electricity generator & $50(87.7)$ & $33(100)$ & $83(92.2)$ \\
\hline \multicolumn{4}{|l|}{ Physical conditions } \\
\hline Cracks in the wales & $2(3.5)$ & $33(100)$ & $35(38.8)$ \\
\hline Signs of water drainage & $57(100)$ & $33(100)$ & $90(100)$ \\
\hline Signs of humidity & $2(3.5)$ & $2(6)$ & $4(4.4)$ \\
\hline Cleaned storage room & $47(82.4$ & $25(75.7)$ & $72(80)$ \\
\hline Availability of instrument to measure temperature & $32(56.1)$ & $19(57.5)$ & $51(56.6$ \\
\hline Proper ventilations & $46(80.7)$ & $29(87.8)$ & $75(83.3)$ \\
\hline Over stocked items on the shelves & $20(35)$ & $21(63.6)$ & $41(45.5)$ \\
\hline Temperature documentation & 0 & $2(6)$ & $2(2.2)$ \\
\hline Storing of control drugs separately & $20(35)$ & $14(42.5)$ & $34(37.7)$ \\
\hline poor quality items & $10(17.5)$ & $4(12.1)$ & $14(15.5)$ \\
\hline
\end{tabular}

such a way as to reduce the introduction, generation, and retention of contaminants within the area [12].

Furthermore, $57 \%$ of warehouses had instruments to measure the temperature. The room temperature in the warehouse must not exceed $25-30^{\circ} \mathrm{C}$. It must be controlled, measured, and recorded on the appropriate sheet every day so devices used to measure temperature must themselves be controlled, and possibly tested. Thermometers should be placed in areas where temperature fluctuations are the widest that is to say near openings [7].

As mentioned in the literature review, if temperature deviates outside the relevant recommended conditions for an extended time, the temperature of the warehouse should be monitored to provide suitable storage conditions and to ensure the stability of drugs [3,21]. This result means, nearly half of them do not measure warehouse temperature, which is an inappropriate practice that requires corrections according to the international standards.

No medical warehouses had instruments to measure relative humidity. To reduce the effects of humidity, temperature and relative humidity should be controlled, monitored, and recorded, where relevant, to ensure compliance with requirements pertinent to the materials and products, and to provide a comfortable environment for the operator where necessary. Maximum and minimum room temperatures and relative humidity should be appropriate [11]

Extremes of humidity and temperature should be avoided. High humidity $\left(>60 \% \mathrm{RH}\right.$ at $\left.21^{\circ} \mathrm{C}-24^{\circ} \mathrm{C}\right)$ produce more lasting effects on the drug component, for example, capsule shell since as moisture is absorbed, the capsules become softer, tackier, and bloated. If temperature is increased, the capsule shells may melt and fuse together. High temperature $>40^{\circ}$ in a dry place may cause cracking of the capsule shell. Therefore, capsules should be stored in an air-conditioned area in which the humidity does not exceed $45 \% \mathrm{RH}$ at $21^{\circ} \mathrm{C}-24^{\circ} \mathrm{C}$ [8].

"What you cannot measure, you cannot managed" so proper instrument should be used to measure relative humidity in the warehouse with daily documentation to ensure relevant conditions according to international standards.

Checklist observations also showed that $86.6 \%$ of the warehouses had enough light (Table 5). Effective lighting permits all operations to be carried out accurately and safely [12]. Many active ingredients are light sensitive, especially solutions that should be kept in their packaging. No product should be directly exposed to daylight [7].

Regarding ventilation system, the checklist showed that $83 \%$ of warehouses had enough fans, air conditioner in the store. Airconditioned store designed with cooling plant sized ensure internal temperatures maintained below $25^{\circ} \mathrm{C}$ to ensure the quality pharmaceutical products $[22,23]$. Temperature, relative humidity, and ventilation should be appropriate and should not adversely affect the quality of pharmaceutical products during their storage [8].

The results showed that $45 \%$ of storerooms had overstocked items on shelves. Stored drugs and disposable neatly on shelves and pallets, however, more than $60 \%$ of overstock items was in NGOs warehouses and many boxes set on the floor. This was inconsistent with the guideline of the WHO in 1993 that showed a pharmaceutical product should be stored off the floor and suitably spaced to permit cleaning and inspection to enable correct storage and to avoid possible loss a systematic storage of the delivered goods used of pallets for better air circulation [24]. Provision of spaces allows people and/or forklift pallets to circulate. A sufficient space should be left for each pharmaceutical product to avoid mixings and to incorporate new items that are not in stock yet. The products with the furthest expiration dates should be stored at the back of the shelves, and the ones with nearest expiration dates should be shelved in the front. This enables the reduction of the risk related to the expiration of the product use-by date during storage; boxes should be perfectly piled up while limiting the height to prevent collapses. It should be stored in such a manner so that their labels are easily visible and readable. All boxes in stock should be closed. For every shelved product, only one box should be opened for the distribution [7].

The results derived from the checklist showed that $38 \%$ of the controlled drugs are kept in a separate controlled storage space. This means more attention should be paid to this issue to prevent theft, assault, missuse, and lost. These products should be managed independently based on management tools notably, to these products and under the responsibility of a pharmacist. Narcotics and other controlled products should be stored separately, in a locking cabinet (or little room), which should be guarded by the Responsible Pharmacist [7].

The guideline of John Snow Inc. confirmed that there are specific procedures in place for the procurement, reception, storage, dispensing, 
Table 5: Differences between warehouses type by the warehouses status and systems

\begin{tabular}{|c|c|c|c|c|c|c|c|}
\hline Dependent variables "Warehouse status" & Independent variables (warehouse type) & $\mathbf{n}$ & Mean & $\mathbf{P}^{*}$ & SD & t & $\mathbf{p}$ \\
\hline \multirow[t]{2}{*}{ Construction (12) } & Private & 57 & 10.193 & 84.90 & 2.15007 & 3.368 & 0.001 \\
\hline & Local NGOs & 33 & 8.3939 & 69.90 & 2.88248 & & \\
\hline \multirow[t]{2}{*}{ Stock quality control process (11) } & Private & 57 & 6.5614 & 59.60 & 1.26798 & 4.586 & $<0.001$ \\
\hline & Local NGOs & 33 & 7.7879 & 70.70 & 1.13901 & & \\
\hline \multirow[t]{2}{*}{ Stores management system (4) } & Private & 57 & 1.7719 & 44.20 & 0.5675 & 0.318 & 0.751 \\
\hline & Local NGOs & 33 & 1.8182 & 45.20 & 0.80834 & & \\
\hline \multicolumn{8}{|l|}{ Checklist } \\
\hline Storage condition (8) & Local NGOs & 33 & 4.2424 & 53 & 1.25076 & & \\
\hline \multirow[t]{2}{*}{ Physical conditions (12) } & Private & 57 & 3.5263 & 29.30 & 3.59119 & 0.09 & 0.929 \\
\hline & Local NGOs & 33 & 3.4545 & 28.70 & 3.77567 & & \\
\hline
\end{tabular}

*Mean percentage. SD: Standard deviation

and administration of controlled substances. Special ordering forms should be used to regulate storage process in the warehouse [3]. On the other hand, control drugs must establish access-controlled storage; this will probably include storing the products in a separate locked room, cabinet, or safe locked wire cage within the storage facility [24]. The study of Chambers in 2006 showed that less than half of warehouses stored controlled drugs in a secure place to prevent misuse of drugs by following national regulations that define in great detail the type of cabinet or safe required. Controlled drugs must be stored in a doublelocked cabinet, with or without a red light [25].

Checklist observation showed that $15.5 \%$ of storeroom had poor quality items, which means that drugs and/or disposable without label opened and expired. Hence, effective measures should be in place to ensure that rejected, and/or expired materials and pharmaceutical products cannot be used or bypassed. They should be stored separately from other materials and pharmaceutical products while awaiting their disposal either by destruction or by return to the supplier [4].

\section{Warehouse type and warehouse requirements}

The construction quality is $85 \%$ at private storage, while it is only $70 \%$ at local storage. There were statistically significant differences between the warehouse type and warehouses constructions (** $\mathrm{p}=0.001)$, with higher mean score (10.19) for private warehouses than the local NGOs warehouses (8.39). These results may be due to required documents, in which private warehouse ought to satisfy many requirements to get the license granted from accreditation and licenses of $\mathrm{MoH}$, while local NGOs is granted the license that requires less demand and requirements that's because $\mathrm{MoH}$ considered these warehouses as a charity organization.

Furthermore, about $71 \%$ of local NGOs and $60 \%$ of private warehouse manage and control their stock properly while with statistically significant differences between warehouse type and warehouses stock management and control $(\mathrm{p} \leq 0.001)$, with higher mean scores (7.78) for local NGOs warehouses than the private warehouses (6.56).

The quality of warehouse management system was $45 \%$ in private warehouse as well as local NGOs, and the results show that there were no statistically significant variations in reference to warehouse type and warehouse systems/requirements $(\mathrm{p}=0.751)$. This result may be attributed to the absence of any guideline and using of the same system and regulation following Ministry of Health and Palestinian National Authority regulation

In addition, the quality of storage control was $53 \%$ for local NGOs and $45 \%$ for private warehouses. The results showed there were statistically significant differences between warehouse type and their storage conditions and their safety and security $(\mathrm{p}=0.046)$, with higher mean scores (4.24) for local NGOs warehouses than the private warehouses (3.63). Hence, buildings should have sufficient security to prevent pilferage of the pharmaceuticals. Safety procedures relating to all relevant aspects including, for example, the safety of personnel and property, environmental protection, and product integrity should be in place. These results are consistent with the study conducted in Lebanon by the WHO, which showed that the central medicines warehouse had no security management system in place, no monitoring on entry and exit, no alarm system, and no security system is used [20].

Regarding physical conditions and warehouse type, both private and local NGOs warehouses had poor conditions (29\%), and there is no statistically significant variations were noticed among the different warehouses $(\mathrm{p}=0.929)$ and observation results confirmed no difference between all warehouses as most of them were clean and used shelves, good ventilation, and light.

\section{CONCLUSION}

Non-governmental and private medical supplies warehouses are considered as the key component of the medical storage and delivery of pharmaceuticals and medical preparation in Gaza Governorates. Most warehouses do not have conducive and adequate storage space and medicines are stored in areas that may lead to fast deterioration.

The assessment has found that medical supplies in the warehouse are not stored adequately according to good storage practice whereby stocks are not under secure systems, while there is fully protection from sunlight, properly ventilated, well organized, and clean. There is inadequate functioning system for cold storage, Information and Telecommunication System is in place, which manages the stocks for medical store department. Most of the employees working in the warehouses did not received training courses about the requirement to operate the equipment medical supplies storage.

There is a need for application of scientific inventory management tools for effective and efficient management of the medical warehouses according to the international standard of good storage practice.

\section{AUTHORS CONTRIBUTIONS}

Tabash conceived of the presented idea. Tabash developed the theory and performed the computations. Abuqamar verified the analytical methods. Tabash supervised the findings of this work. All authors discussed the results and contributed to the final manuscript.

\section{CONFLICT OF INTERESTS}

The authors declare that there is no conflict of interest regarding the publication of this paper.

\section{REFERENCES}

1. Goel H, Asa PK, Gupta A, Garg C. A drug warehouse management system. Int J Multidiscip Res Dev 2013;3:18-30.

2. Kokilam MB, Joshi HG, Kamath VG. Assessment of pharmaceutical store and inventory management in rural public health facilities - A study with reference to Udupi District, Karnataka. Pharm Methods 2015;6:53-9.

3. World Health Organization. Guidelines for the Storage of Essential 
Medicines and Other Health Commodities. Arlington, Va.: John Snow Inc. U.S. Agency for International Development; 2003

4. Ahmed E, Al Mansoori B. Good Pharmaceutical Storage and Distribution Practice. United Arab Emirates: Drug Control Department, Ministry of Health; 2004.

5. World Health Organization. Drug Distributors, Drug Wolesalers and Drug Storage Warehouses. USA: Louisiana Company; 1993.

6. Siyoi F, Mohamed I, Ochieng WO, Wanjala P, Mwatu W. Guidelines for Good Distribution Practices for Pharmaceuticals. Kenya: Pharmacy and Poisons Board; 2006.

7. Pharmaciens Sans Frontiers. PSF Pharmaceutical Guide How Better to Manage Pharmaceutical Warehouse. France: Technical Document; 2003.

8. World Health Organization. Guideline for Good Storage Practices in Medical Stores and Hospitals. Ministry of Health and Population, Faculty of Pharmacy. Cairo, Egypt: Cairo University, World Health Organization; 2004. Available from: http:/www.eda.mohp.gov.eg/ Files/375 GDP.pdf. [Last accessed on 2017 Feb 17].

9. Al-Geeg W. Evaluation of Governmental Central Medical Warehouse Management System. [Master Thesis]. Palestine: School of Public Health, AL Quds University; 2004.

10. Nasim S, Maaz SM, Ali F, Khan MA. Inventory management through lean logistics and warehousing techniques. Int J Manag Sci Bus Res 2016;5:2226-8235

11. Kareem S, Taha M. Guidelines on Good Distribution and Transportation Practice of Medicinal Products. Sudan; 2005.

12. World Health Organization. WHO Expert Committee on Specifications for Pharmaceutical Preparations. Geneva: Technical Report; 2006. p. 937.

13. Ministry of Health. Health Conditions in the Occupied Palestinian Territory. East Jerusalem, Palestine: Ministry of Health 2009

14. Egyptian Ministry of Health. Guideline for Good Distribution Practices for Pharmaceutical Products. Cairo: General Pharmaceutical Inspections; 2009
15. World Health Organization. Initial Health Needs Assessment War on Gaza. Geneva: World Health Organization; 2009.

16. Prasath A. Inventory management through extended star-ring supply chain network. Int J Pharm Pharm Sci 2017;

17. Ko Z, Dobrova YE. Process model of the trial site quality management system. Asian J Pharm Clin Res 2016;9:225-8.

18. Chau KW, Cao Y, Anson M, Zhang J. Application of data warehouse and decision support system in construction management. Autom Constr 2003;12:213-24.

19. Health Canada. Guidelines for Temperature Control of Drug Products during Storage and Transportation. Canada: Health Products and Food Branch Inspectorate; 2011. Available from: https://www.canada. $\mathrm{ca} / \mathrm{content} / \mathrm{dam} / \mathrm{hc}-\mathrm{sc} / \mathrm{migration} / \mathrm{hc}-\mathrm{sc} / \mathrm{dhp}-\mathrm{mps} / \mathrm{alt}$ formats/pdf/ compli-conform/gmp-bpf/docs/GUI-0069-eng.pdf. [Last accessed on 2017 Feb 11].

20. World Health Organization. Measuring Transparency to Improve Good Governance in the Public Pharmaceutical Sector. Lebanon: World Health Organization; 2009a.

21. Mitema S, Kikuvi G. Antimicrobial storage conditions. J Antimicrob Chemother 2005;55:595-6.

22. World Health Organization. Handbook for Drug Supply Management at the First Level Health Facility. Division of Child Health and Development. Geneva: World Health Organization; 1997.

23. World Health Organization. Managing Drug Supply: The Selection, Procurement, Distribution, and use of Pharmaceuticals. USA: Kumarian Press; 1997.

24. World Health Organization. How to Estimate Warehouse Space for Drugs. Geneva: World Health Organization; 1993.

25. Chambers A, Allan C, Birks R, Collett B, Curran J, Edwards C, et al. Controlled Drugs in Perioperative Care. Portland Place, London: The Association of Anesthetists of Great Britain and Ireland; 2006. Available from: https://www.aagbi.org/sites/default/files/controlleddrugs06_0. pdf. [Last accessed on 2017 Feb 11] 